Quaderni di Geografia Cahiers de Gécongaty rataphie

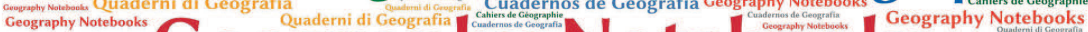
Cuadernos de Geografia Geography Notebooks $U 201000$ Cahiers de Géographi Cahiers de Géographie cahiers de Géographie Cuadernos de Geografía Cahiers de Géographie Cahiers de Géographie Cuadernos de Geografía Geography Notebooks

\author{
$4(2021)$ \\ 1 \\ Teatro di suoni. \\ Spazi acustici teatrali e territoriali
}

A cura di

Martino Mocchi, Lorena Rocca, Demis Quadri and Carlotta Sillano

EDITORIAL

Teatro di suoni per l'attaccamento ai luoghi. Uno sguardo geografico 11

Lorena Rocca

Per un teatro di suoni. Riflessioni su possibili dimensioni sonore nelle 23 creazioni site-specific di physical theatre

Demis Quadri

INTRODUCTION

Teatro di suoni. Spazi acustici teatrali e territoriali

Demis Quadri e Lorena Rocca

SPECIAL Issue

I suoni di Mantova come strumenti di interpretazione del paesaggio.

Tra turismo sostenibile ed educazione al patrimonio culturale

Valeria Pecorelli, Franca Zuccoli, Alessandra De Nicola, Enrico Squarcina

Il paesaggio sonoro campano tra contemporaneità e nuove forme

di progettualità turistica

Germana Citarella 
La narrazione spettacolarizzata del paesaggio sonoro.

Da Giuseppe Chiari a Philip K. Dick e oltre

Francesco Michi

Musica di paesaggi sonori. Enunciazione, risignificazione, comunicazione

Carlotta Sillano

Camminare per ascoltare. Partiture invisibili del territorio abitato

Elisabetta Senesi

Il paesaggio sonoro in relazione. Suono, movimento e immagini per stimolare complessità percettiva Angela Calia

Groove Fields. Understanding the Dance Floor from an Art-Based Research Perspective

Sebastian Mattbias

Il silenzio come esperienza trasformativa. L'importanza del silenzio nella meditazione e in ambito professionale

Sebastiano Caroni

Progettare il silenzio. Una lettura acustica dell'ex villaggio sanatoriale 125 Morelli a Sondalo

Martino Mocchi

Voicing One's Will. Theatre as Audio-Visual Hypotyposis of the Poetic

Michael Groneberg

Music and Clowning in Europe, 20th-21st centuries

Anna Stoll Knecht

Il paesaggio sonoro nella composizione musicale. Un percorso bibliografico

Stefano Alessandretti

\#exploreART: il labirinto di A. Pomodoro e i bambini. Un progetto di fruizione condivisa con percorsi sensoriali partecipati Alessandra De Nicola, Franca Zuccoli 


\section{OTHER EXPLORATIONS}

Il rumore lontano. Intervista a Lorena Rocca

a cura di Martino Mocchi

Re Cervo. Intervista a Antonella Astolfi

a cura di Krizia Bonaudo e Demis Quadri

Centovalli-Centoricordi. Intervista a Oliviero Giovannoni a cura di Krizia Bonaudo e Demis Quadri

Alla ricerca di un metodo: Open Space Technology 



\title{
Groove Fields. \\ Understanding the Dance Floor from an Art-Based Research Perspective
}

\author{
Sebastian Mattbias \\ HafenCity University Hamburg \\ DOI: https://doi.org/10.7358/gn-2021-001-matt
}

\begin{abstract}
This contribution examines groove dynamics across various spatial contexts such as the dance club and the artistic performance space. As groove dynamics do not occur in a spatial vacuum but are embedded in affective environments, they need to be approached from an interdisciplinary perspective that ties together findings from experimental field studies, performance studies, musicology, cognitive hermeneutics etc. and places them in the physical, anatomic and acoustic contexts of concrete dance situations. In that way, the dance floor can be understood as a space of entanglements where acoustic, movement and kinaesthetic grooves mark and create a fluid territory of improvisational interaction and communication.
\end{abstract}

Keywords: groove; bounce; entrainment; improvisation; club dance.

\section{INTRODUCTION}

In rhythmic music, groove usually describes the urge to bounce or dance along. The groove experience is the main reason why people visit clubs with electronic dance music every weekend. The DJ's performance and his beats seem to be the determining factor for the party to generate the 
joy and exuberance of the collective dance. The mighty hum of the bass makes a plausible case for the dominance of the music over the dance. However, the timid nature of attempts to open the dance floor at the beginning of a party or the heaviness that arises when people leave the dance floor, point towards the basic need of a functioning interaction in collective dancing. If it seems easier to dance together than to dance alone, then it is because of the organisation in the assembly of movements that generates groove in the first place. The groove feeling is determined by the diffused interaction of movements that constantly synchronise and de-synchronise with each other. This dynamic process of movement communication generates a sensation of ease or creativity. It is created through an affective field of movement - a territory of interaction - in which the intertwined movements become the collective performance of groove. The dance floor as a territory marks spatially the space where dancers are "inside" the collective communication process (Delaney $2005,14)$ - the space in which they are affected and affecting each other -, but also territory as an "act" (Wise 2000, 299) where movements create a distinct space which expresses a specific sensation for its occupants.

Just like it is never certain whether a groove will establish at a party or not, or if everybody present will experience it as such, the groove dynamic is hard to analytically pin to specific examples. As a particularly subjective and ephemeral phenomenon, groove dynamics and their movement relations are tied to personally felt experiences. How can they be traced or any data be generated to build an argument on, when groove cannot be captured in an image or video amidst the various activities on the dance floor. Since there isn't the one groove, but rather groove dynamics and principles of interaction, research on the groove phenomenon needs to find alternative approaches. The somatic and subjective nature of the groove experience on the dance floor requires a research design that combines systematic observations on the one hand and practical try outs on the other. Research on the groove experience is an example of how theatre and the performing arts can be a platform for experimental Humanities and how knowledge production within the arts can be productively linked to understanding acoustic spaces and their performativity.

In the following article, I will retrace my interrelated artistic and academic research on movement relations in club dance. Based on the phenomenon of groove, I will offer a model to explain and analyse how dance and the interlaced action dynamics are organised in the club. I have conducted basic research from a dance studies perspective in an interrelated 
research design combining various setups following a Participatory Art Based Research approach (PABR 2021). PABR understands research as a triangular relation and interaction between art, science and society. It uses the means and methodologies of art for practical exploration within questions from the Humanities, while valuing knowledge drawn from everyday practices and life experience as equal to academic or artistic kinds of knowledge. In clubs qualitative field studies were conducted, linked with laboratory studies in a dance studio, and hypotheses tested in performances. These three lines of inquiry were the foundations for my argumentation. The findings presented here are based on movement logs and questionnaires with a participative research approach, used in field studies in the clubs Berghain, about blank and Chesters Music Inn in Berlin. The outlined action dynamics and organising principles from the club were then translated into theatre performances that could be understood as testing sites for the translatability of groove dynamics into other contexts. The groove spaces-series (Matthias, synekism/groove space, 2014, maneuvers/groove space, 2014, chorus/groove space, 2015, volution/ groove space, 2015, x/groove space, 2016) as a theatre of sound form a choreographic perspective from the performing arts that understands the dance floor as an interrelated acoustic-movement space and exposes its performative dimension.

These performances do not illustrate the theoretical deliberations on the club or try to recreate a specific groove situation from a club, but rather use the dynamics identified in clubbing as a choreographic tool and test them in performance. Therefore, in the following, I link examples from my artistic practice with my academic reflections. Movement experiments come together with artistic and academic findings. The transfer from club to art, however, remains an artificial step and only unhinges some aspects of the club phenomenon. Still, based on audience feedback and my observations of around 90 performances, the assumption is reinforced, that the movement relations generating groove in the club are a self-contained movement phenomenon that is not only limited to club dancing.

\section{Groove AS Entrainment}

In clubs, dancers synchronise their bodies with the layering patterns of rhythm. With an attitude of expectation in the circular beats, they completely or partially follow the musical structure in that very mo- 
ment. When it feels easy and good to dance, this is described as groove (Pressing 2002, 288). Originally derived from Jazz, the term combines movement with the perception of music, but also a successful interplay of musicians (Pfleiderer 2006, 301; Berliner 1994, 353). When in the groove the head - seemingly of its own accord - starts to bounce to the beat, Jessica Philipps-Silver et al. speak of "acoustic entrainment" (Phillips-Silver, Aktipis, and Bryant 2010, 2). Following Philipps-Silver entrainment is the capacity of human perception to connect an external periodic stimulus to a motoric synchronising. Through the link between sound and movement the sensing of time and comparing different intervals are facilitated for perception through the entrainment process. With the help of acoustic entrainment, movement motifs are easily placed into the musical matrix. They are structured by a fluid interrelation of movement motifs and the multi-layered rhythm patterns. In club dancing, the correct placement of the legs in space does not matter, but what principles guide the improvisations?

In an attempt to isolate the kind of dancing in clubs one can find in the 'bounce' a movement motif that can be seen as a basic form of club dancing. Bounce is a form of a physical rhythm pattern that brings the body into a continuous springy vibration. Due to the elastic tension in the muscles the weight springs up again and again after each drop on the beat. When bouncing, the legs remain in a movement loop that brings the body into a constant quality of falling and elevating again. A slight flexion of the arms and spine transfers the movement impulse to the rest of the body and brings it into a bouncing quality of movement. The anatomical consequences of impulse transmission get the whole body moving without direct planning and control. This constant full body movement activates the proprioceptive sense that is informed by nerve endings in the joints and the skin (O'Shaughnessy 1995, 194). The awareness of the position of body parts in space and with it the feeling of one's own body is amplified either through targeted attention control - e.g. when I think about my legs - or like in the case of the bounce through differentiation of sensations through movement. If dancers are 'carried away' by the rhythm of a house or dub step and fall into a bouncy-like movement in their entrainment, the dancers experience the beat interval of house or a dub step in their body completely differently due to different transmission waves that activate their proprioception differently. The inner feeling of the groove in the music gets a somatic or kinaesthetic evidence through motor synchronization. Through their 
movement participation the listeners feel the acoustic space kinaesthetically. It materializes as a felt space with a distinct quality. The elastic character has also another function for the dancers that can be better understood through an amplified and abstracted version. In synekism/ groove space (Matthias, synekism/groove, 2014) we dissected the effective elements of bounce and created an alternative 'dance' version in the studio as a dance laboratory.

Harumi Terayama is keeping her body in a supported but elastic posture (Fig. 1). With a small release in the muscles like in the bounce she lets herself fall into her hip without fully collapsing the whole body. The tendons and muscles stretch on the complementing side as the upper body collapses slightly, sequentially reorienting the posture into a new position with her head down and on one knee. In the supported posture this stretch springs back and erects part of the collapsed body parts so that in the new and re-erected position a new drop can be initiated. The small fall of the hip brings a large amount of body into movement and a new positioning that the dancer can follow without

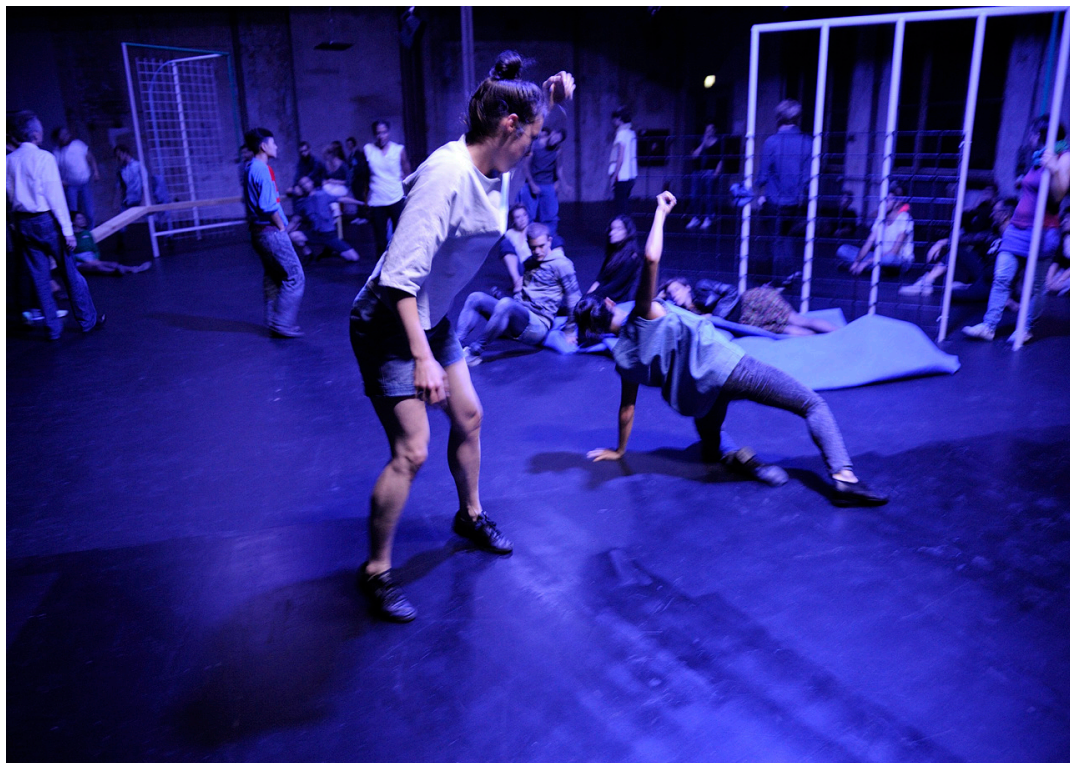

Figure 1. - Harumi Terayama with Lisanne Goodhue in synekism/ groovespace at Sophiensäle Berlin 2014. Photograph: Arne Schmidt () Sebastian Mattbias. 
controlling where it will end up. Terayama continuously follows her resulting movements that are a residue from the drop to the new positioning that she can witness and be surprised by. The supported but elastic quality of the body creates a fluidity of movement that interconnects impulses and resulting movements.

Like in this example, club dancing also results in anatomic consequences. Through the elastic body tension, initiating movements lead the dancers to expansions of space, changes of direction, isolation or a change in the movement dynamic. When a dancer follows the consequences of the impulses in their body and traces the anatomical conditions, it brings them into new positions of their body parts that they didn't plan before. Bormann et. al. have presented in other forms of improvisation how the «improvisers can surprise themselves with their own actions, and thereby become spectator and listener of their own actions and their consequences» (Bormann, Brandstetter, and Matzke 2010, 13). In club dancing, the permissive attitude helps the dancers to be surprised by their own dance, rather than pre-planning and controlling their movements paths. However, the dance moves constantly need to be aligned with the coordination to the music and also retain the fluid physicality of the dancing style. It is this fluid quality that is created within the elastic posture that marks the character of club dancing. The fluid quality of movement together with the relation between impulses and resulting movements amplify the kinaesthetic experience for the dancer and facilitates the element of surprise from one's own actions described above. This process of synchronising ones own surprising movements is intertwined with music synchronisation. Through the help of entrainment and human anatomy the acoustic space becomes physically tangible and explorable in the dancers' body.

\section{GROOVE FIELDS: ALIGNMENTS OF QUALITY PROGRESSIONS}

My field studies showed that within a club context it feels easier for volunteers to keep dancing in the proximity of other dancers (Matthias 2018,82 ). In the environment of movement, a feeling of relief in the movement effort or a reinforcement of own movement impulses can occur for the individuum (Matthias 2018, 136). For example, it is difficult to stand still on the packed dance floor (Matthias 2018, 87). Since entrainment is activated by different modalities, it seems plausible that 
also visual stimuli can be linked to motor synchronising. Entrainment in music is based largely on the circular beat structure. So, how can a movement space - the concrete place of the dancefloor - have entrainment capacities? How is synchronising possible with so many short-lived, diverse and changing movements in proximity? In chorus/groove space (Matthias 2015) the affective quality of a moving environment was tested without a circular beat structure highlighting the organizing principles in visual entrainment processes and the affectiveness of physical space.

In chorus/groove space (Fig. 2), 20 performers walked with a continuous thrust in the hip in wide curves through the space. The thrust in walking was accompanied by a pressured kind of singing that pushes more air out than one would normally need. The continuous and held pitches together with the walk affected in many performances the audience to walk with the performers into a huge moving vortex. The many performances were a testing site wherein it seemed that there was a supportive effect of the environment of the thrusted walk without a structure of beat intervals. In my experience and based on audience feedback, a somatic evidence could be established in the performance space.

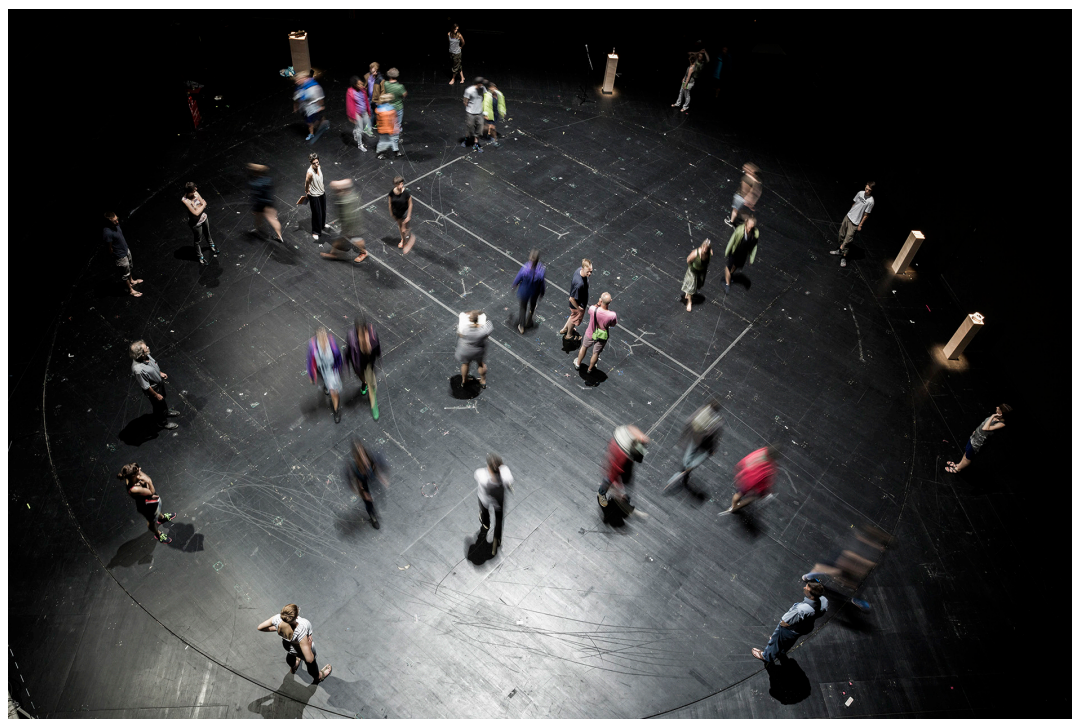

Figure 2. - chorus/groove space at Theater Freiburg, 2015. Photograph: Florian Brocca (C) Sebastian Matthias. 
In order to explain this from the perspective of movement, I would like to follow Liz Waterhouse's et al. differentiation of dance cues from dance alignments. Cues are in entrainment the coordination of temporal starting points like when someone is counted in. Movement impulses or retracting movements are synchronised with the metric beats. Further, Waterhouse et al. defines the following or re-tracing the qualitative progression of movement as alignment (Waterhouse, Watts, and Bläsing $2014,14)$. Unlike with gestural movement sequences or cues, within alignment the whole progression needs not be recognised and waited for. Instead, the process of communication draws on a qualitative movement mode in order to synchronise. Correlating qualitative progressions of different moving bodies consolidate and interlink into a field, and it doesn't seem to matter whether an arm or head are exercising the movement mode. As can be identified in horizontal swinging steps in the club context (Matthias 2018, 103) and exemplified above in a simplified and abstract way, the temporary alignment of the qualitative progressions in the forward thrust help the dancers push their movement. Through entrainment perception the dancers interlink their motor movements with their environment. This field of movement generates an ease of moving. When the head bounces with the movement or sways from side to side, only short snippets can be seen from the continuous improvisations. The short visual contacting in the shifting gaze between referees functions as a collective frame of reference that the dancers can consistently lean on. The specific relations between effort, movement progression and time structure constitute the movement mode, just like in the example from chorus/groove space in a thrust of walking, or a bounce or swing that can be located throughout the dancing motifs. I would like to define this movement mode as movement quality. This qualitative progression is an inherent part of the somatic or felt character of the groove field and marks its performative character.

Dance movements that stimulate others and reinforce themselves do not have a causally determined effect that the clubbers are at the mercy of. When the music stops, they are still able to keep a Bounce in their spine, if that is their intention. The dancers are not moved 'automatically' by the dance or the music, like marionettes, but feel a pleasure when they do link. By allowing the effects of moving environments, visual entrainment in the form of alignment can be as stirring as music. It draws from similar ways of acoustic processing and connects visual stimuli with motoric synchronising. 


\section{Reinforcing And Connecting}

In the club, groove fields are not as homogenous as in the context of the artistic performances of groove space. They can temporarily emerge as such even in the club, but in the club context overlapping fields dominate, where processes of entrainment with different movement qualities plurally cross over. The overlapping groove fields not only facilitate the movements, but the group of dancers around can potentiate the consequence of the collectively danced movement quality in the resulting movements, enlarging the effect of the interplay between movement impulses and resulting movements that was explained above. The transfer of impulses is collectively reinforced, so that the resulting movement differentiates more fully and expands. The impulse to move is indeed derived from the music, but in the consequence of the collectively reinforced transfer the resulting movement can reach an autonomy that does not follow acoustic entrainment. Similarly, to an ornament, the movement develops e.g. from a swing to a push through the anatomy of the body. An expansion e.g. of the spatial trajectory of the movement evokes a coordination of the body that initiates new movement motifs to the music with its new quality, and brings about new turns in the improvisation.

The following organisation processes cannot easily be tested within the performing arts context with audiences as the dancers need the freedom to change their movement quality. In order to create the following principle, it needs everyone's intention to dance collectively and to change their movement motifs. If the 'new' differentiated movement quality of the resulting movement meets an overlapping correlating groove field in its vicinity, another entraining synchronising occurs. The resulting movement can stabilise a new movement motif before it is recognised as such by the dancers. The resulting movement in the single dancers' body interacts with the surrounding environment and the collective dance floor can shape and guide the subjective improvisation.

In the dynamic of the collective dance and the reinforcement of the groove field, a consequence occurs in the dancers' bodies that drives the conscious intention to dance on like a motor. Through the entanglement of ornaments in overlapping groove fields, an infinite loop can establish itself, in which the not yet consciously danced movement pushes into the improvisation through the collective reinforcement. A feeling of groove occurs, in which the body manifests in an insatiable source of movement generation. Only the movements that interlink are repeated creating a feeling of belonging over time in which the groove sensation can be 
sustained. Among overlapping groove fields within the boundary of the dancefloor the space becomes kinaesthetically meaningful. Thus, it could be called a kinaesthetic territory (Delaney 2005, 14). J. Macgregor Wise claims when analysing the territory of bome that territories have "subject effects": "The space called home is not an expression of the subject. Indeed, the subject is an expression of the territory, or rather the process of territorialisation» (Wise 2000, 301). Similarly, in the interaction between resulting movement and groove field the subject experience is created through the dance floor. So, the dancing is not the expression of the dancer or the music, but also an expression of the dance floor as a territory. This expressive territory then influences the DJ's performance and his or her musical decisions creating a feedback loop as a "booth and floor interaction" (Fikentscher 2000, 80).

\section{THE DANCE FLOOR AS A SPACE OF ENTANGLEMENTS}

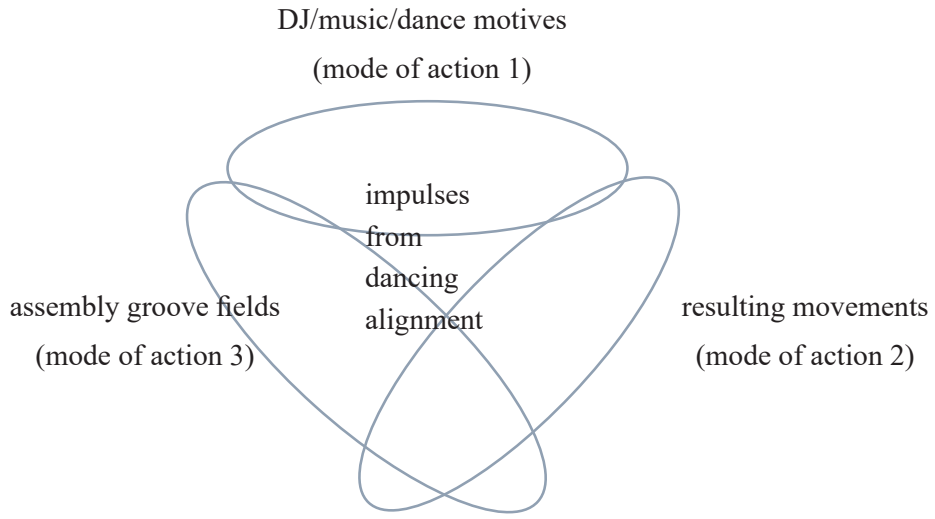

Figure 3. - Groove Field. Made by the author.

Regarding the groove experience, we can thus assume an activity in which three continuous streams of information cross over and reinforce each other in perception and action. The acoustic processing of the cyclic music, e.g. with the legs, the reinforcing synchronising of dance in the 
environment, and the tracing of one's own body that constantly challenges perception with new postures in its fluid elaboration of the movement motifs. From this perspective the dance floor is an intertwined field of acoustic, movement and kinaesthetic grooves marking a territory of interaction and communication (Fig. 3).

The movement results are implicit in the impulse-giving sounds and movements, and this in turn only becomes a stimulus-giving movement through multiplication in the environment it encountered as a movement ornament. The chaining plural communication does not arise between the sender and the receiver, it is not binary, but singular and plural at the same time. The movement motif as a reference has no starting point within the logic of groove's linked dynamic of action. An origin cannot be located. A dancer has no position from which a give and take in the improvisation can occur (van Eikels 2013, 333). In the simultaneous transmission of movements, only those who were already created in a previous movement are amplified, and their reinforcing groove field only arises if this movement could previously be productive for other actors. The movement modes - stable movement quality, movement ornament and plurally increased movement quality - are effective at the same time, and dancers are in the mode of groove in all three positions at the same time. This mobile location is a scattered position in this communication network (Serres 1992, 198). The flow of information received and sent, is kinaesthetically perceived everywhere in and around the ornamental parts of the body. The dancers are parallel in a multitude of groove fields, in a multitude of times and also in the musical matrix - an acoustic and territorial space.

This conclusion could only be graspable in the interactive research process between theatre and field studies. Isolation and abstraction, as well as testing with audiences, where important aspects in guiding and forming my understanding of this complex and affective space. The Theatre of Sound that I see in the different dance performances were the crucial step in my research process to understand the dance floor as an affective overlapping groove field.

\section{REFERENCES}

Berliner, P.F. 1994. Thinking in Jazz - The Infinite Art of Improvisation. Chicago: University of Chicago Press. 
Bormann, H.F., G. Brandstetter and A. Matzke. 2010. "Improvisieren: eine Eröffnung.” In Improvisieren: Paradoxien des Unvorhersebbaren. Kunst - Medien - Praxis, edited by Hans-Friedrich Bormann, Gabriele Brandstetter, and Annemarie Matzke, 7-19. Bielefeld: transcript.

Delaney, D. 2005. Territory: A Short Introduction. Malden: Blackwell.

van Eikels, K. 2013. Die Kunst des Kollektiven: Performance zwischen Theater, Politik und Sozio-Ökonomie. München: Wilhelm Fink.

Evert, K et al. 2021. "What is PABR?”. In K. Evert, M. Gunsilius, S. Matthias, S. Peters, K. Wildner eds. Participatory Art Based Research. Online available on: www. pab-research.de.

Fikentscher, K. 2000. 'You Better Work!' Underground Dance Music in New York City. Hanover: Wesleyan University Press.

Matthias, S. 2018. Gefüblter Groove: Kollektivität zwischen Dancefloor und Bübne. Bielefeld: transcript.

Pfleiderer, M. 2006. Rhythmus: psychologische, theoretische und stilanalytische Aspekte populärer Musik. Bielefeld: transcript.

Phillips-Silver, J., C. Athena Aktipis and G. Bryant. 2010. “The Ecology of Entrainment: Foundations of Coordinated Rhythmic Movement". Music Perception 28 (1): 3-14. doi: https://doi.org/10.1525/mp.2010.28.1.3.

Pressing, J. 2002. "Black Atlantic Rhythm: Its Computational and Transcultural Foundation”. Music Perception 19 (3): 285-310. https://doi.org/10.1525/ mp.2002.19.3.285.

Serres, M. 1992. Hermes II: Interferenz. Berlin: Merve [transl. Michael Bischoff].

O'Shaughnessy, B. 1995. "Proprioception and the Body Image". In The Body and the Self, edited by Jose Luis Bermudez, Naomi M. Eilan and Anthony J. Marcel, 175204. Cambridge: MIT Press.

Waterhouse, E., R. Watts and B.E. Bläsing. 2014. "Doing Duo: A Case Study of Entrainment in William Forsythe's Choreography 'Duo". Frontiers in Human Neuroscience 8 (812): 1-16. doi: https://doi.org/10.3389/fnhum.2014.00812.

Wise, J.M. 2000. “Home: Territory and Identity”. Cultural Studies 14 (2): 295-310. doi: https://doi.org/10.1080/095023800334896. 